\title{
Tissue Distribution and Uptake of Endogenous Lipoprotein Triglycerides in the Rat*
}

\author{
Samuel J. Friedberg $†$ and E. Harvey Estes, Jr. \\ (From the Cooperative Lipid Laboratory and Radioisotope Unit, Veterans Administration \\ Hospital, and the Department of Medicine, Duke University Medical Center, \\ Durham, N. C.)
}

Circulating free fatty acids (FFA) are in part taken up by the liver and released again as fatty acid esters transported in the blood as lipoproteins $(1-5)$. The first of these esters to appear is triglycerides, which are followed in turn by cholesterol esters and phospholipids (6). The liver is the principal source of the circulating triglycerides formed from plasma FFA ; other tissues contribute minimally if at all to the process $(5,7)$. When serum containing these labeled triglycerides is reinjected, they are to a large extent quickly taken up by the liver, and a rapid exchange between plasma and liver triglycerides apparently takes place (3).

Recently, Havel, Felts, and Van Duyne have evaluated the fate of reinjected endogenously formed circulating labeled triglycerides associated with lipoproteins of density (D) $<1.006$ (8). They found that radioactivity appeared in most tissues and that the tissue distribution of the label seemed to be the same as that found after injection of chylomicrons.

Our investigation provides data, in the rat, on 1) the serum lipoprotein distribution of triglycerides formed after injection of radioactive palmitate, 2) the tissue distribution of the reinjected

* Submitted for publication March 23, 1963 ; accepted September 26, 1963.

This investigation was supported in part by a grant from the Life Insurance Medical Research Fund; by a research grant, HE-04807, and a training grant, HTS5369, from the National Heart Institute, U. S. Public Health Service; a research grant, A-5509, from the National Institutes of Health, U. S. Public Health Service; and by the Regional Center for the Study of Aging, grants M-2109 and H-3582, Duke University Medical Center.

Presented in part at the national meeting of the American Federation for Clinical Research, Atlantic City, N. J., April 1962.

$\dagger$ This work was done during the tenure of an established investigatorship of the American Heart Association. labeled triglycerides, 3) the in vitro uptake of these endogenously formed triglycerides by adipose tissue, 4) the possible influence of the liver on peripheral tissue uptake of endogenous triglycerides, 5) the rate of oxidation of the endogenous circulating triglycerides, and 6) the transformation of radioactive palmitate to other fatty acids in the process of ester formation.

\section{Methods}

Triglyceride- $\mathrm{C}^{14}$ lipoprotein was obtained by injecting 50 to $80 \mu \mathrm{c}$ of albumin-bound palmitic acid-1- $\mathrm{C}^{14} 1$ into the jugular vein of fed rats anesthetized with pentobarbital. The rats had been previously maintained on a $\mathrm{Pu}$ rina laboratory chow containing 3.95 to $4.12 \%$ fat. The albumin-bound radioactive palmitate was prepared as previously described (9); the $1-\mathrm{ml}$ volume injected contained $10 \%$ by weight of human albumin. Thirty minutes later blood was aspirated from the abdominal aorta through a 20-gauge needle. A maximal amount of blood was obtained by injecting 5 to $10 \mathrm{ml}$ of physiological saline through the needle after the first withdrawal. This maneuver immediately restored respiration and circulatory integrity and permitted more complete exsanguination. The serum obtained, which contained 1 to $3 \%$ cholesterol ester and phospholipid activity, was layered under saline (D 1.006) and centrifuged for 30 minutes at $105,000 \times g$. The top centimeter of the saline layer was removed with a tube slicer to eliminate chylomicrons and extremely low density particles. The infranatant fluid was then adjusted to D 1.063 with saturated sodium chloride solution of known density and centrifuged for 18 to 20 hours at $105,000 \times g$ in the 40 rotor of the Model L Spinco preparative ultracentrifuge (10). The lipoprotein layer was removed with a tube slicer, stored in the refrigerator, and used within 4 days. The activity of each batch was determined. Contamination by $\mathrm{C}^{14} \mathrm{O}_{2}$ or $\mathrm{C}^{14}$ bicarbonate in the lipoprotein solution was determined by methods previously described (11) and was found to represent $0.3 \%$ of the total activity, which was

${ }^{1}$ Obtained from New England Nuclear Corp., Boston, Mass. SA, 12 to $20 \mathrm{mc}$ per mmole. Methyl ester prepared in this laboratory produced a single mass peak by gas chromatography; in this peak 95 to $100 \%$ of radioactivity was recovered. 
considered negligible. The amount of material obtained from two large rats $(0.6$ to $1.6 \mu \mathrm{c})$ was sufficient to carry out two or three reinjection studies.

The lipoprotein pattern of the $\mathrm{C}^{14}$ triglycerides in the serum obtained from rats given radioactive palmitate was determined by starch block electrophoresis and by ultracentrifugation.

Starch block electrophoresis was carried out by the method of Kunkel and Trautman (12) using barbital buffer at $\mathrm{pH} 8.6$ and 0.05 ionic strength. The starch was washed with at least $4 \mathrm{vol}$ of buffer. Four $\mathrm{ml}$ of serum was applied to large blocks and run for 24 hours at $4^{\circ} \mathrm{C}$ with a constant current of $20 \mathrm{ma}$. In some cases the serum was prestained with $20 \%$ by volume of $1 \%$ Sudan black solution in ethylene glycol. (One-tenth $\mathbf{g}$ Sudan black B was dissolved in $1 \mathrm{ml}$ ethyl acetate. Nine $\mathrm{ml}$ propoylene glycol was then added and the solution was centrifuged.) Stained serum was sometimes run alongside unstained serum on the same block; human serum was also used for comparison. Migration of albumin was visually followed with an ultraviolet lamp. The prestaining procedure did not interfere with migration. At the conclusion of electrophoresis, the blocks were cut into 5-mm wide and approximately $1-\mathrm{cm}$ high segments and put into test tubes. Four $\mathrm{ml}$ of physiological saline was added, and the proteins were eluted by stirring with a Vortex mixer. Proteins were determined by the method of Lowry, Rosebrough, Farr, and Randall (13), phospholipids by a modification of the micromethod of Bartlett (14), and cholesterol by the technique of Searcy, Bergquist, and Jung (15). Since the radioactive rat serum used for reinjection also contained human albumin, which migrates at a different rate, the chemical determinations were also performed on ordinary rat serum.

Radioactivity peaks were located on smaller starch blocks to which $0.2 \mathrm{ml}$ radioactive rat serum was applied. The blocks were cut into small segments and eluted with $3 \mathrm{ml}$ saline as above. Activity was determined by drying $0.5-\mathrm{ml}$ samples in scintillation vials. Two $\mathrm{ml} 0.5 \mathrm{M}$ Hyamine $10 \mathrm{X}$ solution was added. After 6 hours, $4 \mathrm{ml}$ ethanol and $12 \mathrm{ml}$ phosphor solution were added and the samples were counted. Other samples were used for protein determination.

The ultracentrifugal pattern of the radioactive lipoproteins was obtained as follows. One $\mathrm{ml}$ of serum was pipetted into each of three $\frac{1}{2}$ - by $2 \frac{1}{2}$-inch lusteroid tubes. One tube was filled with saline of D 1.006. The other two were brought to $\mathrm{D} 1.019$ and 1.063 , respectively. The tubes were centrifuged for 19 hours at 40,000 rpm in the 40.3 rotor of the Spinco Model L preparative ultracentrifuge. One tube containing $1 \mathrm{ml}$ rat serum was half filled with sodium chloride solution of D 1.006 . The mixture was then overlaid with $3 \mathrm{ml}$ of sodium chloride solution of D 1.006 and centrifuged 30 minutes at $40,000 \mathrm{rpm}$. The top centimeter in depth of each tube was sliced off in the Spinco tube slicer. Infranatant and supernatant solutions were extracted with Dole's extraction mixture. The free fatty acids were isolated from the infranatant extracts by the method of Borgström
(16). All fractions were dried in scintillation vials and counted.

Rats weighing about 200 .g, also maintained on Purina laboratory pellet diet containing 3.95 to $4.12 \%$ fat, were anesthetized with pentobarbital. They were neither fasting nor given an unusual carbohydrate load because we wished under the present circumstances to obtain data from animals in a more physiological state of nutrition. One and one-half $\mathrm{ml}$ of the hypertonic lipoprotein solution containing a measured amount of radioactivity was injected into a neck vein over a period of 5 minutes. The hypertonic load produced no deaths, evidence of shock, or other gross ill effects. Only a prompt diuresis occurred. The animals were exsanguinated through the abdominal aorta after 10, 30, 60, and 120 minutes. The activity of the lipids in the blood present in the various organs and tissues was determined by means of $\mathrm{I}^{131}$ albumin as previously described by Bragdon and Gordon (17). $\mathrm{I}^{131}$ samples were counted in a Packard autogamma counter.

In several animals, injection of label was preceded by performance of a functional hepatectomy according to a procedure described by Borgström and Olivecrona in which the superior mesenteric artery and then the vessels of the porta hepatis are ligated (5).

Various organs and tissues were removed as rapidiy as possible, then weighed and extracted by grinding in 20 vol of cold chloroform: methanol $(2: 1$, vol : vol). Muscle was obtained from the thigh and adipose tissue from the perinephric region. The extracts were washed with a $40 \%$ vol of $2 \% \mathrm{KH}_{2} \mathrm{PO}_{4}$ and dried on a rotary evaporator. The dried extracts were then brought to volume with ligroin in 10- or 25-ml volumetric flasks, and a sample was taken for silicic acid chromatography. In general the lipids were separated into phospholipids and into a fraction eluted with ethyl ether containing glycerides, FFA, cholesterol, and cholesterol esters. For our purpose it was not advantageous or practical to separate the ethyl ether fraction into all its components except in a few instances. The ethyl ether fraction always contained a small amount of activity in the FFA, and, as will be seen under Results, very little activity appeared in cholesterol esters. Samples were counted in a Packard Tri-Carb liquid scintillation spectrometer, and an internal standard of either $\mathrm{C}^{\mathbf{1 4}}$ benzoic acid or $\mathrm{C}^{\mathbf{1 4}}$ toluene was used to measure the absolute activity of the samples. A correction was made for the activity in blood remaining in the various tissues.

Excretion of $\mathrm{C}^{14} \mathrm{O}_{2}$ was measured by putting the anesthetized animal in a jar through which oxygen from a tank was passed. The effluent gas was led through a dry ice and acetone trap to remove water vapor and then bubbled through $5 \mathrm{ml}$ of $0.5 \mathrm{M}$ hydroxide of Hyamine $10 \mathrm{X}$ in a $10-\mathrm{ml}$ graduated cylinder. Two $\mathrm{ml}$ of the Hyamine solution was added to $15 \mathrm{ml}$ of phosphor for liquid scintillation counting.

In a study designed to evaluate the uptake of lipoprotein triglycerides in vitro, epididymal fat pads of rats were incubated in $5 \% \mathrm{CO}_{2}$ and air in Krebs-Ringer bicarbonate buffer at $\mathrm{pH}$ 7.4. The hypertonicity of the 
radioactive solution was reduced by diluting fivefold with buffer. Incubation was carried out for 5 hours at $37^{\circ}$. The uptake of radioactivity was compared with that of fat pad immersed for a few seconds in boiling water. The specific activity of the triglycerides in the incubation mixture was $208,000 \mathrm{dpm}$ per $\mathrm{mg}$.

Estimates of the total radioactivity in serum, muscle, and adipose tissue were based on published values for the relative proportions of these tissues in rats of various weights and ages (18). Adipose tissue was taken as $5.6 \%$, muscle as $45.5 \%$, and plasma volume as $3.5 \%$ of body weight.

To evaluate whether or not fatty acid residues of esters formed had undergone transformation to other fatty acids, the liver lipids of animals that had received palmitic acid-1- $\mathrm{C}^{\mathbf{1 4}} 30$ minutes previously were examined by gas liquid chromatography. Chloroform methanol liver lipid extracts were transferred to $25-\mathrm{ml}$ culture tubes that had screw caps fitted with polytetrafluoroethylene (Teflon) liners. About $10 \mathrm{ml}$ of methanol containing $2 \%$ sulfuric acid was added. The tubes were tightly closed and the lipids transmethylated in a heating block at $80^{\circ} \mathrm{C}$ for 4 hours. The methyl esters were extracted with petroleum ether after $5 \mathrm{ml}$ of water was added to the mixture. The petroleum ether extract was then dried with a stream of nitrogen, and a few drops of benzene were added. The methyl esters were kept in frozen benzene.

Gas liquid chromatography was carried out with a gas chromatograph ${ }^{2}$ using a katharometer detector and an eight foot stainless steel column, i.d., $\frac{1}{4}$ inch, packed with $20 \%$ by weight ethylene glycol succinate coated on Chromosorb W. ${ }^{3}$ A stream splitter was not used. Fractions were collected with a fraction collector. The cartridges were packed loosely with glass wool instead of the anthracene supplied. Recovery in this system was excellent as long as the silicone rubber gasket that seals the nozzle of the changer onto the cartridges remained soft. A good seal was assured by frequent changing of the gasket and application of extra manual pressure to the nozzle. Better than $95 \%$ recovery of standard methyl palmitate $\mathrm{C}^{\mathbf{1 4}}$ was obtained in ten consecutive runs with this system. Background was $20 \mathrm{cpm}$. After collection of fractions, the cartridges were placed in scintillation vials, and $15 \mathrm{ml}$ phosphor solution was forced through the cartridge with a $50-\mathrm{ml}$ syringe fitted with a $1-\mathrm{cm} 20$-gauge needle passing through a silicone rubber seal. The cartridges were left in the vials during counting.

\section{Results}

Lipoprotein distribution of endogenously formed serum triglycerides. Ultracentrifugal evaluation of the labeled lipid-lipoprotein material obtained from rats given albumin-bound radioactive pal-

\footnotetext{
${ }^{2}$ Research Specialties Co., Richmond, Calif.

3 Johns-Manville Corp., New York, N. Y.

4 Packard Instrument Co., La Grange, Ill.
}

TABLE I

Ultracentrifugal serum lipoprotein separation and localization of endogenous triglycerides recovered after iv injection of albumin-bound radioactive palmitate

\begin{tabular}{cccc}
\hline & $\mathrm{A}$ & $\mathrm{B}$ \\
\hline & & \\
\hline & &
\end{tabular}

Tube I

$\begin{array}{lrr}\text { Lipoproteins D* }<1.006 & 125,216 & 253,992 \\ \text { Non-FFA lipoproteins D }>1.006 & 25,140 & 3,495 \\ \text { FFA in fraction D > 1.006 } & 11,303 & 26,707\end{array}$

Tube II

Lipoproteins $\mathrm{D}<1.019$

$1.019 \quad 2,965$

Tube III

Lipoproteins $\mathrm{D}<1.063$

FFA in fraction D > 1.063 $\quad 9,854 \quad 27,479$

${ }^{*} \mathrm{D}=$ density.

mitate revealed, in one study, that $93 \%$ of the nonFFA label was found in the fraction $\mathrm{D}<1.019$ and $83 \%$ in the fraction $\mathrm{D}<1.006$. Approximately $5 \%$ of the label was recovered as free fatty acid from the fraction $\mathrm{D}>1.063$. Very little lipoprotein label remained in the fraction of D 1.019 to 1.063 and D $>1.063$ (Table I, column A). In another ultracentrifugal study, with blood pooled from two animals, $98 \%$ of the nonFFA label was found in the fraction $\mathrm{D}<1.006$. No additional activity was found in the supernatant fluid at D 1.019 (Table I, column B).

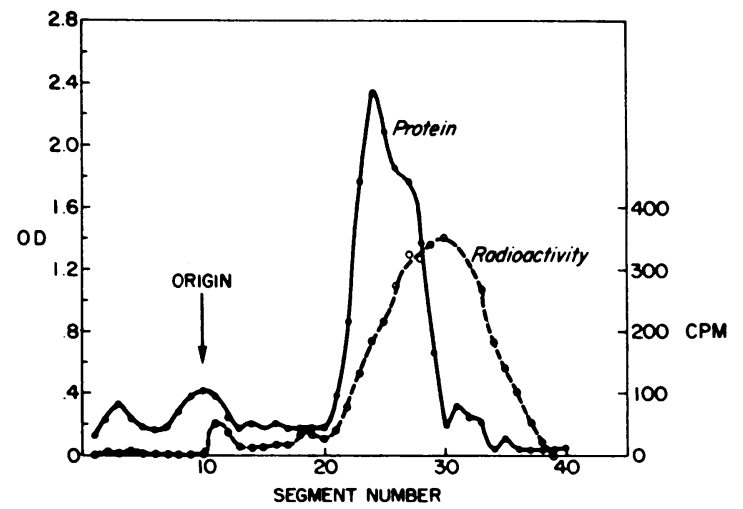

Fig. 1. Starch block electrophoresis. Location of radioactivity in relation to serum proteins in starch block electrophoresis of rat serum from rat given human albumin-bound $\mathrm{C}^{\mathbf{1 4}}$ palmitate iv 30 minutes previously. Large protein peak represents mixture of human and rat albumin. 


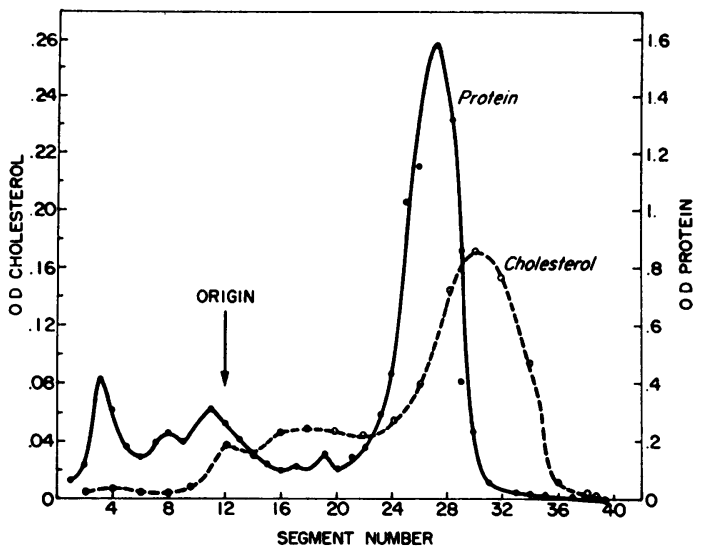

Fig. 2. Starch BLOCK electrophoresis. Location of cholesterol in relation to rat serum proteins separated by starch block electrophoresis. Large protein peak is albumin.

Starch block electrophoresis revealed that radioactivity was concentrated in a single peak that migrated faster than albumin and corresponded to a band heavily stained with Sudan black (Figure 1). The same area contained phospholipid and cholesterol peaks (Figure 2). There was considerable trailing of cholesterol and radioactivity from the origin, but there were no other distinct peaks, in contrast to human serum in which three lipoprotein bands were observed. The amount of trailing activity was greater than the fraction of counts that corresponded to beta lipoprotein by the centrifugal study (D 1.019 to D 1.063). These trailing counts were therefore not considered to represent beta lipoproteins.

When the rat serum was overlaid with sodium chloride solution of D 1.006 and centrifuged for 30 minutes at $40,000 \mathrm{rpm}, 45 \%$ of total serum radioactivity was recovered in the top centimeter in depth of the tube. When a similar preparation was spun for 15 minutes at $9,500 \times g$, only negligible activity was recovered in the supernatant fluid. Such treatment is sufficient to clear serum of chylomicrons and of grossly visible lipemia (19).

These studies reveal that the radioactivity released into serum after injection of radioactive palmitate resides mostly in the fraction of $D$ $<1.006$ and has an electrophoretic mobility near albumin on starch block. No band corresponding to beta lipoprotein was observed, and the absence of beta lipoprotein activity was confirmed by the finding of little activity in the fraction D 1.019 to
1.063. The material reinjected into recipient animals, therefore, contained low density lipoproteins (mostly $\mathrm{D}<1.006$ ) minus chylomicrons and larger particles of $\mathrm{D}<1.006$ that had been removed by preliminary spinning under a saline layer at 40,000 rpm and at D 1.006 for 30 minutes.

Uptake of triglycerides by liver. Injected lipoprotein triglycerides were taken up rapidly by liver (Table II) during the first 10 minutes. A considerable fraction was converted to phospholipids, although the largest fraction remained in the glyceride and fatty acid proteins. At $30 \mathrm{~min}$ utes the amount of activity present was essentially the same as after the first 10 minutes, representing between 25 and $41 \%$ of the amount of label injected. The fraction present as phospholipid also remained essentially unchanged during the first 30 minutes and represented 21 to $39 \%$ of total

TABLE II

Activity in liver after administration of lipoprotein triglyceride- $C^{14}$

\begin{tabular}{lcrrr}
\hline \hline \multicolumn{1}{c}{ Time } & $10 \mathrm{~min}$ & $30 \mathrm{~min}$ & $\mathbf{6 0} \mathrm{min}$ & $\mathbf{1 2 0} \mathrm{min}$ \\
\hline & \multicolumn{1}{c}{$\%$} & \multicolumn{1}{c}{$\%$} & \multicolumn{1}{c}{$\%$} & \multicolumn{1}{c}{$\%$} \\
Injected radio- & 22.0 & 25.9 & 27.8 & 11.9 \\
activity recovered & 25.9 & 24.7 & 26.6 & 25.7 \\
in liver & & 29.1 & 7.2 & 7.0 \\
& & 41.3 & 18.0 & 1.3 \\
Injected radio- & 7.3 & 7.5 & 8.8 & 8.2 \\
activity recovered in & 7.8 & 9.6 & 11.1 & 11.9 \\
liver phospholipids & & 6.0 & 0.8 & 2.9 \\
& & 15.5 & 2.2 & 0.8 \\
\hline
\end{tabular}

liver lipid activity. During this period of time, very little phospholipid was released by the liver, as the fraction of serum activity in phospholipid and total serum phospholipid activity remained unchanged.

By the end of 60 and 120 minutes, considerable activity could still be found in some cases, but in others, it had declined to as low as $1.3 \%$ of injected label. One liver contained $25.7 \%$ of injected label after 120 minutes. Phospholipid content was also quite variable but in general represented a larger proportion of liver lipid activity at 2 hours.

Gas liquid chromatography of methyl esters of liver lipids showed that $2.7 \%$ of radioactivity was found in stearate and $1.08 \%$ in oleate. Less than $1 \%$ of activity was found in myristate (Figure 3 ). 


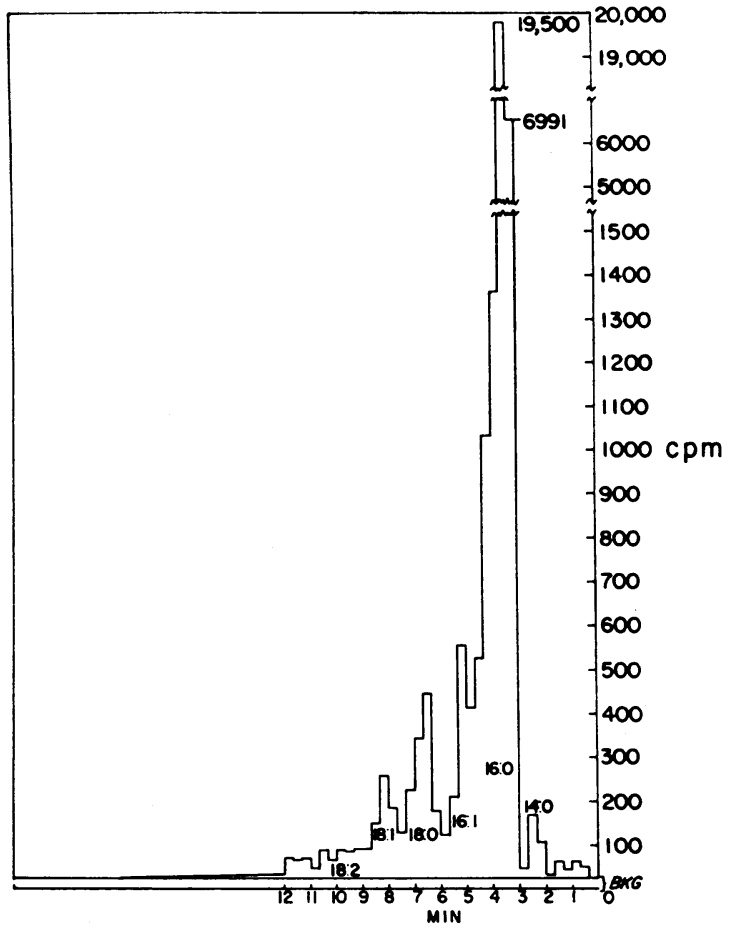

Fig. 3. ACtivity IN LIPIDS SEPARATED BY GAS LIQUid CHROMATOGRAPHY ON ETHYLENE GLYCOL SUCCINATE. Column temperature, $195^{\circ} \mathrm{C}$. Helium flow pressure, 15 pounds per square inch. Katharometer detector. 14:0= myristic acid; $16: 0=$ palmitic acid; $16: 1=$ palmitoleic acid; $18: 0=$ stearic acid; $18: 1=$ oleic acid; $18: 2=$ linoleic acid. $\mathrm{BKG}=$ background.

We did not determine the extent to which direct formation of stearic and oleic acids from palmitate or resynthesis from acetate had occurred. The presence of labeled myristate indicated that reformation from acetate derived from the breakdown of carboxyl-labeled palmitate had taken place. Such synthesis from acetate could therefore account for label in other fatty acids.

Activity in serum. Table III records the activity in serum triglyceride, fatty acid, and phospholipid over a period of 2 hours. The small amount of phospholipid activity initially measured in serum represented phospholipid activity of the injected material. The total amount of serum phospholipid activity remained essentially the same during the study. At 10 minutes, 20 and $32 \%$ of total injected activity remained in serum, and at 30 minutes, 14 to $38 \%$ remained. After 2 hours serum activity ranged between 0.8 and $7 \%$ of injected activity, with three of the four values
TABLE III

Total rat serum activity after iv administration of lipoprotein triglyceride- $C^{14}$

\begin{tabular}{lcccc}
\hline \multicolumn{1}{c}{ Time } & $10 \mathrm{~min}$ & $30 \mathrm{~min}$ & $\mathbf{6 0} \mathrm{min}$ & $120 \mathrm{~min}$ \\
\hline & $\%$ & $\%$ & $\%$ & $\%$ \\
Injected radio- & 20.3 & 32.2 & 5.9 & 0.8 \\
activity recovered & 31.5 & 38.3 & 6.5 & 7.0 \\
in serum & & 37.1 & 3.8 & 2.3 \\
& & 13.8 & 2.7 & 1.1 \\
Injected radio- & 0.7 & 0.5 & 0.3 & 0.4 \\
activity recovered in & 0.7 & 0.6 & 0.3 & 0.4 \\
serum phospholipids & & 0.6 & 0.4 & 0.7 \\
& & 0.5 & 0.3 & 0.7 \\
Injected radio- & & 0.78 & 0.17 & 0.11 \\
activity recovered & & & 0.39 & 0.44 \\
in serum FFA & & & 0.71 & \\
& & & 0.13 &
\end{tabular}

$2.3 \%$ or less. FFA label remained low at all time intervals studied. These data were obtained from separate experiments.

Uptake by adipose tissue and muscle. Five per cent of injected label was found in adipose tissue after 10 minutes (Table IV). At 30 minutes the amount of label present was as high as $13 \%$; at 60 minutes and 120 minutes, as much as $20 \%$ and as little as $1.7 \%$ were found. The amount of phospholipid label was small, averaged $0.56 \%$ of the amount of label injected, and appeared to follow no particular trend with time except to remain constant within a relatively narrow range. The amount of label taken up per gram of adipose tissue averaged 3.5 times the amount taken up per gram of skeletal muscle (Table V).

The amount of label found in muscle ranged from 2.5 to $15.4 \%$ of injected label (Table VI). Ten of fourteen determinations were found to range from 6.3 to $15.4 \%$. The low values were

TABLE IV

Activity in adipose tissue after administration of lipoprotein triglyceride- $C^{14}$

\begin{tabular}{lcrrr}
\hline \multicolumn{1}{c}{ Time } & $10 \mathrm{~min}$ & $30 \mathrm{~min}$ & $60 \mathrm{~min}$ & $120 \mathrm{~min}$ \\
\hline & $\%$ & $\%$ & $\%$ & $\%$ \\
Injected radio- & 4.6 & 12.6 & 20.0 & 16.8 \\
activity recovered & 4.8 & 4.8 & 11.0 & 2.3 \\
in adipose tissue & & 2.0 & 3.5 & 2.5 \\
& & 11.9 & & 1.7 \\
Injected radio- & 0.7 & 0.9 & 0.8 & 0.6 \\
activity recovered in & 1.2 & 0.3 & 0.5 & 0.1 \\
adipose tissue phos- & & 0.4 & 0.1 & 0.3 \\
pholipids & & 0.3 & & 1.1 \\
\hline
\end{tabular}


TABLE V

Uptake of lipoprotein triglyceride-C $C^{14}$ per gram of adipose tissue and muscle in seven rats

\begin{tabular}{rc}
\hline \hline Muscle & Adipose \\
\hline$d p m$ & $d p m$ \\
330 & 2,410 \\
376 & 1,070 \\
147 & 1,150 \\
672 & 813 \\
1,628 & 2,840 \\
651 & 3,046 \\
667 & 1,188
\end{tabular}

confined to the first 30 minutes after injection; activity tended to be higher at 60 to 120 minutes. Activity in phospholipid was high, ranging from 20.0 to $53.2 \%$ of the total muscle activity, with an average of $39.5 \%$.

Formation of cholesterol, cholesterol esters, monoglycerides, diglycerides, and activity in FFA. Cholesterol ester activity of liver and total carcass (Table VII) was determined by column silicic acid chromatography and by thin layer chromatography on silica gel. After 2 hours, $0.13 \%$ to $0.7 \%$ of total injected activity was found in this fraction in the carcass. After 30 minutes, $0.12 \%$ of injected activity was found in liver and at 2 hours, $0.11 \%$. That very little activity was incorporated into cholesterol esters was confirmed by thin layer chromatography. In addition, free cholesterol, monoglyceride, diglyceride, and FFA activities in liver were very low. These findings clearly indicate that phospholipid and triglyceride activity predominated to the extent that the ethyl ether fraction separated by column chromatography represented mostly triglyceride activity.

Tissue distribution of lipoprotein triglycerides after functional hepatectomy. Although access of

TABLE VI

Activity in muscle after administration of lipoprotein triglyceride- $C^{14}$

\begin{tabular}{lcccc}
\hline \hline \multicolumn{1}{c}{ Time } & $10 \mathrm{~min}$ & $30 \mathrm{~min}$ & $60 \mathrm{~min}$ & $120 \mathrm{~min}$ \\
\hline & $\%$ & \multicolumn{1}{c}{$\%$} & $\%$ & $\%$ \\
Injected radio- & 9.9 & \multicolumn{1}{c}{3.0} & 6.3 & 10.4 \\
activity recovered & 2.5 & 3.2 & 7.4 & 8.2 \\
in muscle & & 3.4 & 7.5 & 11.6 \\
& & 15.4 & 9.5 & 8.8 \\
Injected radio- & 4.6 & 1.5 & 1.4 & 4.8 \\
activity recovered in & 1.2 & 1.7 & 2.8 & 3.1 \\
muscle phospholipids & & 1.2 & 2.7 & 5.3 \\
& & 5.6 & 1.9 & 3.5 \\
\hline
\end{tabular}

TABLE VII

Carcass and liver cholesterol ester activity in per cent of administered dose

\begin{tabular}{ccc}
\hline \hline Carcass & $\%$ & hours \\
1 & & \\
2 & 0.13 & 2 \\
3 & 0.7 & 2 \\
Liver & 0.5 & 2 \\
1 & & \\
2 & 0.12 & $\frac{1}{2}$ \\
\hline
\end{tabular}

administered label to the liver was greatly reduced by occluding the circulation to this organ, the uptake of lipoprotein triglycerides by adipose tissue and muscle was not inhibited. Under these circumstances some activity could still be found in the liver, but the quantity was reduced to about $2 \%$ of administered label. Formation of phospholipids proceeded in the various tissues to the same extent as in the intact rats (Table VIII).

Uptake of lipoprotein triglycerides by epididymal fat pad in vitro. The ability of adipose tissue to take up lipoprotein triglycerides directly was evaluated by incubating the latter with rat epididymal fat pads in Krebs-Ringer bicarbonate buffer at $\mathrm{pH} 7.4$ in an atmosphere of air and $5 \% \mathrm{CO}_{2}$. Five per cent of the label in the medium was taken up after 5 hours, and fat pad boiled for 30 seconds was inactive (Figure 4). Whereas 3\% of the label in the incubation medium consisted of phospholipid activity, $10 \%$ of the label in the fat pads was found in the phospholipid fraction. We calculated that fat pad was able to take up about $1.3 \mathrm{mg}$ of triglyceride per gram of adipose tissue in 5 hours under the conditions of the study.

Oxidation. Excretion of $\mathrm{C}^{14} \mathrm{O}_{2}$ after iv administration of lipoprotein triglyceride $\mathrm{C}^{14}$ reached a maximum in 30 to 45 minutes and remained con-

TABLE VIII

Activity in adipose tissue and muscle 30 minutes after administration of lipoprotein triglyceride in three functionally hepatectomized rats

\begin{tabular}{lrrr}
\hline & 1 & 2 & 3 \\
\hline & $\%$ & $\%$ & $\%$ \\
Dose in muscle triglyceride and FFA & 8.4 & 16.8 & 6.7 \\
Dose in muscle phospholipid & 14.0 & 4.6 & 1.5 \\
Dose in adipose triglyceride and FFA & 4.0 & 6.8 & 8.6 \\
Dose in adipose phospholipid & 0.2 & 0.1 & 0.4 \\
\hline
\end{tabular}




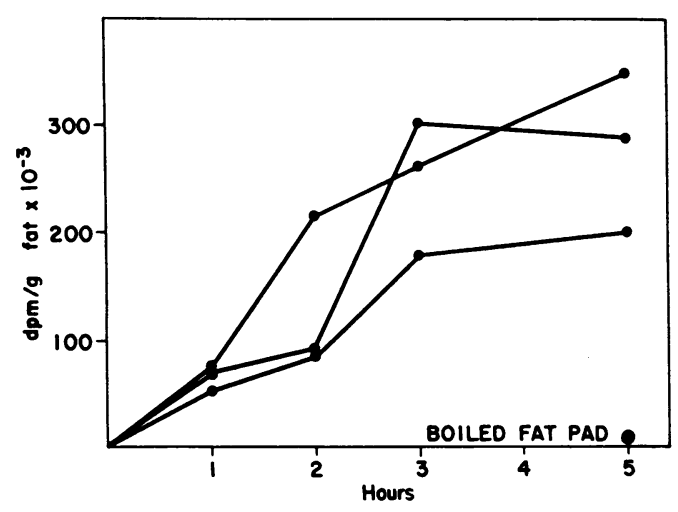

FIG. 4. In vitro FAT PAD UPTAKE OF LIPOPROTEIN TRIGLYCERIDE.

stant up to 2 hours. In the 2 animals studied, the results were almost identical: Under the conditions of the procedure, with animals lightly anesthetized by pentobarbital sodium (Nembutal), $11 \%$ of the administered dose was excreted in 2 hours. The maximal excretory rate reached was $6.9 \%$ per hour. This figure, as would be expected, lies between the values found by Bragdon (20) for starved versus carbohydrate force-fed rats and reflects the metabolic state of the rats used in this study.

\section{Discussion}

Data previously reported from our work (21) indicated that the labeled serum triglycerides obtained after injection of radioactive palmitate were beta lipoproteins. This evaluation was made on the basis of paper and starch block electrophoresis after centrifugal flotation in a medium of D 1.063. The present results indicate that these triglycerides cannot be classified in this category but belong to the class of lipoproteins mostly of $\mathrm{D}$ less than 1.006. Electrophoretically these rat lipoproteins migrate on starch block near albumin and would be classified as having either alpha 1 or alpha 2 mobility. In man this ultracentrifugal fraction $(\mathrm{D}<1.019)$ moves as alpha 2 lipoprotein on starch block (22). The earlier data were obtained after reinjection of material containing all lipoproteins of $\mathrm{D}<1.063$. The results obtained in terms of the tissue distribution of this fraction were the same as in the present study, even though the material used in this study did not include a large portion of lighter lipoproteins of $\mathrm{D}<1.006$. These findings are in agreement with those of Havel and co-workers, who obtained similar data in rabbits after the reinjection of lipoprotein triglycerides of $\mathrm{D}$ less than 1.006. Furthermore, as also noted by Havel, there is no obvious qualitative difference in the tissue distribution noted in the present study and that observed after injection of chylomicron triglycerides (8).

The results of the studies on the lipoprotein distribution of the labeled triglycerides indicate that centrifugation in a medium of D 1.063 was unnecessary to separate the labeled fraction. Centrifugation at D 1.019 would have sufficed, since only a small percentage of labeled triglyceride had a D between 1.019 and 1.063. This fact was established late in the course of these studies. Injection of $1.5 \mathrm{ml}$ of the hypertonic solution, timed over a period of 5 minutes, must have been a benign procedure, as no animals died or showed any obvious evidence of circulatory embarrassment. No doubt some initial expansion of blood volume took place. However, prompt filling of the bladder was noted, and since rats are able to concentrate the urine to $3,000 \mathrm{mOsm}$ per $\mathrm{L}$, rapid fluid compartment readjustment probably occurred. The extent to which the initial changes in blood volume altered the calculated serum activity levels must remain unknown. That relatively small plasma volume changes would invalidate the broad conclusions presented here is doubtful.

A fraction of the circulating FFA is converted to triglycerides in the liver, and these triglycerides enter the circulation where they are normally transported mostly in association with lipoproteins exclusive of chylomicrons. The purpose of lipoprotein triglyceride remains unknown, since the needs of tissues for lipids can be met directly by FFA, which turn over far more extensively and rapidly than plasma triglycerides. The transformation of plasma FFA to plasma triglycerides may serve as a mechanism for the disposition of excess circulating FFA, an excess that oxidizing tissues may not be able to accommodate (5); the plasma has only a limited capacity for keeping FFA in solution (from about 150 to $2,000 \mu$ moles per L), whereas enormous quantities of triglyceride may be held (up to 60 or $80 \mathrm{~g}$ per L in hyperlipemia). 
Our study evaluated the uptake of endogenously produced triglycerides by various tissues. We found that a large fraction of label accumulated rapidly in liver, and simultaneously but to a lesser extent, in muscle and adipose tissue. Depending on the tissue examined, considerable variation in the amount of label taken up was observed in the individual experiments. Such differences in uptake could have been due to lack of homogeneity of distribution of label in various tissues, to the effects of anesthesia, to minor variations in dietary state, or to local circulatory differences.

The concentration of label found in adipose tissue and muscle did not undergo the same rate of decline as in liver and plasma, suggesting - as has been considered by other investigators-that the liver and plasma triglyceride pools are in rapid equilibrium, the combined pools feeding peripheral tissues. This notion is also confirmed by the observation that $\mathrm{C}^{14} \mathrm{O}_{2}$ production proceeds briskly 2 hours after injection, a time when liver and plasma triglyceride $\mathrm{C}^{14}$ may be greatly depleted. The extent to which liver phospholipid activity produced from triglyceride $\mathrm{C}^{14}$ re-enters the circulation and is taken up elsewhere remains uncertain from our studies.

The incorporation of triglyceride fatty acid $\mathrm{C}^{14}$ into phospholipid fatty acid proceeded rapidly in muscle but to a much smaller extent in adipose tissue.

Whereas adipose tissue competes poorly with other tissues for FFA particularly in the fasting state, we found that relatively large amounts of lipoprotein triglyceride could be found in adipose tissue. In fact, the concentration of label in adipose tissue was always higher than in muscle. These observations agree with those of Havel and co-workers, who studied lipoproteins of density less than $1.006(8)$. One may conclude that most of the triglycerides taken up by adipose tissue must be released again as FFA, which in turn are taken up once more by liver and other tissues.

Preventing access of lipoprotein to the liver showed that no reconversions in the liver to other lipids or lipoproteins are necessary for the injected lipoprotein triglycerides to gain access to other tissues.

Our studies also demonstrated that the palmitic acid of FFA is not converted to any great extent, if at all, to other fatty acids in the liver.
Although the methyl esters prepared from the radioactive palmitate gave a single peak, the small amount of label found in other fatty acids might well represent impurities present in the original material.

Finally, uptake of lipoprotein triglyceride by isolated epididymal fat pad was demonstrated. This observation also suggests that no further interconversions are needed for such uptake to occur, although hydrolysis of lipoprotein glycerides in the medium could not be ruled out. Note also that phospholipid activity was three times higher in the adipose tissue than in the medium.

\section{Summary}

The tissue distribution of endogenously produced lipoprotein triglyceride was studied in rats maintained on ordinary laboratory pellet diets. At least $95 \%$ of endogenous circulating triglycerides synthesized from circulating FFA are found in lipoproteins of density $<1.019$, with the predominant fraction having a density less than 1.006. Triglyceride activity equilibrated rapidly with liver. Triglycerides re-entered adipose tissue and were taken up by skeletal muscle. Incorporation into phospholipid fatty acid was active in muscle and liver but less so in adipose tissue. Transformation of palmitate to other fatty acids in the formation of triglyceride fatty acid was minimal. The liver performed no essential role in relation to uptake of triglyceride by adipose tissue or muscle. Endogenous formation of lipoprotein triglycericle may be a mechanism for redeposition in adipose tissue of excess circulating free fatty acids.

\section{Acknowledgments}

The authors gratefully acknowledge the technical assistance of Miss Helen Hilderman, Mrs. Marie Dowdee, Mrs. S. S. Goodman, Mrs. Gray Long, and Mrs. Maurine Jones and the assistance of the Medical Illustration Service of the Veterans Administration Hospital, Durham, N. C.

\section{References}

1. Fredrickson, Donald S., and Robert S. Gordon, Jr. Transport of fatty acids. Physiol. Rev. 1958, 38, 585.

2. Stein, Y., and B. Shapiro. Assimilation and dissimilation of fatty acids by the rat liver. Amer. J. Physiol. 1959, 196, 1238. 
3. Laurell, S. Recycling of intravenously injected palmitic acid-1- $\mathrm{C}^{14}$ as esterified fatty acid in the p'asma of rats and turnover rate of plasma triglycerides. Acta physiol. scand. 1959, 47, 218.

4. Hillyard, L. A., C. E. Cornelius, and I. L. Chaikoff. Removal by the isolated rat liver of palmitate-1- $\mathrm{C}^{14}$ bound to albumin and of palmitate-1- $\mathrm{C}^{\mathbf{1 4}}$ and cholesterol-4-C $\mathrm{C}^{14}$ in chylomicrons from perfusion fluid. J. biol. Chem. 1959, 234, 2240.

5. Borgström, Bengt, and Thomas Olivecrona. The metabolism of palmitic acid-1-C $\mathrm{C}^{\mathbf{1 4}}$ in functionally hepatectomized rats. J. Lipid Res. 1961, 2, 263.

6. Friedberg, S. J., R. F. Klein, D. L. Trout, M. D. Bogdonoff, and E. H. Estes, Jr. The incorporation of plasma free fatty acids into plasma triglycerides in man. J. clin. Invest. 1961, 40, 1846.

7. Havel, Richard J., and Alan Goldfien. The role of the liver and of extrahepatic tissues in the transport and metabolism of fatty acids and triglycerides in the dog. J. Lipid Res. 1961, 2, 389.

8. Havel, R. J., J. M. Felts, and C. M. Van Duyne. Formation and fate of endogenous triglycerides in blood plasma of rabbits. J. Lipid Res. 1962, 3, 297.

9. Friedberg, S. J., R. F. Klein, D. L. Trout, M. D. Bogdonoff, and E. H. Estes, Jr. The characteristics of the peripheral transport of $\mathrm{C}^{14}$-labeled palmitic acid. J. clin. Invest. 1960, 39, 1511.

10. DeLalla, Oliver F., and John W. Gofman. Ultracentrifugal analysis of serum lipoproteins in Methods of Biochemical Analysis, David Glick, Ed. N. Y., Interscience, 1955, vol. 1, p. 459.

11. Friedberg, S. J., and E. Estes, Jr. Direct evidence for the oxidation of free fatty acids by peripheral tissues. J. clin. Invest. 1962, 41, 677.

12. Kunkel, H. G., and R. Trautman. Zone electrophoresis in various types of supporting media in Electrophoresis, M. Bier, Ed. New York, Academic Press, 1959, pp. 225-262.
13. Lowry, O. H., N. J. Rosebrough, A. L. Farr, and R. J. Randall. Protein measurements with the Folin phenol reagent. J. biol. Chem. 1951, 193, 265.

14. Marinetti, G. V. Chromatographic separation, identification, and analysis of phosphatides. J. Lipid Res. 1962, 3, 1 .

15. Searcy, R. L., L. M. Bergquist, and R. C. Jung. Rapid ultramicroestimation of serum total cholesterol. J. Lipid Res. 1960, 1, 349.

16. Borgström, B. Investigation of lipid separation methods. Separation of cholesterol esters, glycerides and free fatty acids. Acta physiol. scand. 1925, 25, 111.

17. Bragdon, J. H., and R. S. Gordon, Jr. Tissue distribution of $\mathrm{C}^{14}$ after the intravenous injection of labeled chylomicrons and unesterified fatty acids in the rat. J. clin. Invest. 1958, 37, 574.

18. Castor, W. D., J. Poncelot, A-B. Simon, and W. D. Armstrong. Tissue weights of the rat. I. Normal values determined by dissection and chemical methods. Proc. Soc. exp. Biol. (N. Y.) 1956, 91, 122.

19. Lindgren, F. T., H. A. Elliott, and J. W. Gofman. The ultracentrifugal characterization and isolation of human blood lipids and lipoproteins with applications to the study of atherosclerosis. J. Phys. colloid Chem. 1951, 55, 80.

20. Bragdon, J. H. $\mathrm{C}^{14} \mathrm{O}_{2}$ excretion after intravenous administration of labeled chylomicrons in the rat. Arch. Biochem. 1958, 75, 528.

21. Friedberg, S. J., E. H. Estes, Jr., H. Hilderman, M. Dowdee, and G. Long. The transport and tissue distribution of beta lipoprotein triglyceride (abstract). Clin. Res. 1962, 10, 225.

22. Kunkel, H. G., and R. Trautman. The $\alpha_{2}$ lipoproteins of human serum. Correlation of ultracentrifugal and electrophoretic properties. J. clin. Invest. $1956,35,641$. 